\title{
Mitochondrial DNA Phylogenetics of Black Rhinoceros in Kenya in relation to Southern Africa Population
}

\author{
Elijah K. Githui, ${ }^{1,2}$ David N. Thuo, ${ }^{3}$ Joshua O. Amimo, ${ }^{3}$ \\ Nyamu M. Njagi, ${ }^{2}$ and Maryanne M. Gitari ${ }^{2,3}$ \\ ${ }^{1}$ Institute of Primate Research, P.O. Box 24481, Karen, Nairobi 00502, Kenya \\ ${ }^{2}$ National Museums of Kenya, P.O. Box 40658, Nairobi 00100, Kenya \\ ${ }^{3}$ University of Nairobi, P.O. Box 30197, Nairobi 00100, Kenya \\ Correspondence should be addressed to Elijah K. Githui; kegithui@yahoo.com
}

Received 11 May 2017; Revised 6 July 2017; Accepted 20 July 2017; Published 22 August 2017

Academic Editor: Alexandre Sebbenn

Copyright (C) 2017 Elijah K. Githui et al. This is an open access article distributed under the Creative Commons Attribution License, which permits unrestricted use, distribution, and reproduction in any medium, provided the original work is properly cited.

\begin{abstract}
Black rhinoceros (Diceros bicornis) are highly endangered due to poaching and other anthropological reasons and their protection to rebound the numbers and genetic improvement are necessary remedial measures defined by Rhino International Union of Conservation for the Nature Red List (IUCN). In Kenya black rhino numbers declined from approximately 20,000 in the 1970s to fewer than 400 in 1982. Wildlife conservation managers effected strategies to manage/breed the remaining rhinoceros populations in Eastern and Southern Africa within regional sanctuaries. This study analyzes the genetic variability of these remnant rhinoceros using Mitochondrial DNA (mtDNA). Majority of the rhinoceros in both Kenyan and Southern Africa group are monophyletic clusters with insignificant genetic variations while some lineages are underrepresented. The Eastern Africa rhinoceros forms a distinct clade from the Sothern Africa counterpart while Tanzania population has admixtures. Tajima-D test showed that these two populations are under different selection pressure possibly due to different history of adverse anthropologic activities. Similarly, the Southern Africa rhinoceros have low genetic diversity compared to the Eastern African population due to extended periods of game hunting during Africa colonization. This study suggests that managed translocations of individual rhinoceros across the separated fragments can be applied to improve their genetic diversity.
\end{abstract}

\section{Introduction}

Black rhinoceros (Diceros bicornis) has suffered dramatic decline of all mammals in the recent history and the species is currently categorized as critically endangered in the International Union of Conservation for the Nature Red List (IUCN) $[1,2]$. Between 1960s and 1980s wanton illegal poaching and loss of habitat due to increased human developments in areas that were formerly wilderness resulted in approximately $96 \%$ decline $(65,000$ to 3,800 individuals) in population black rhinoceros across their range in Africa $[3,4]$. In recent years, conservation measures have resulted in increase of in situ black rhino numbers from of 2475 individuals in 1993 to approximately 4880 in 2010 [2, 5, 6].

Kenya Wildlife Service (KWS) records show that these impacts reflected on Kenyan black rhinoceros numbers where catastrophic decline was from an estimated 20,000 individuals in 1970 to 398 in 1991 and then this slightly rebounded to about 631 in 2014 [7, 8]. This was through conservation strategy developed to intensively manage the remaining rhinos within small rhino sanctuaries where KWS periodical translocated the surviving rhinoceros into the high security sanctuaries to limit poaching and enhance breeding $[9,10]$.

Majority of the extant black rhinoceros belong to subspecies Diceros bicornis minor and Diceros bicornis michaeli. Other subspecies include Diceros bicornis longipes and Diceros bicornis bicornis. The D. b. michaeli (eastern black rhino) is found in Kenya and Tanzania while $D . b$. minor is found in Tanzania to South Africa [3, 11]. Although there are apparently no marked geographic or reproductive barriers between the subspecies, they occupy different ecological 
zones. There have not been any rigorous studies on migration and reproductive gene flow between the subspecies although some authors suggest that each subspecies may have distinct genetic or behavioral adaptations to their local environments $[3,12]$.

Genetic differences between related populations can also result from strong genetic drift caused by population fragmentation and declining population sizes [13, 14]. When the genetic structure and historic pattern of gene flow of a species had been described, reintroduction methods can be used to secure locally adapted populations or restocking used for genetic supplementation. Mitochondrial DNA (mtDNA) phylogeny sheds light on founder female populations and can be applied in determining black rhinoceros population relationships across the ecological and geographic zones $[15,16]$. The measure of variability within and between groups is an essential step in determining robust numbers of individuals in a sanctuary that preserves genetic diversity of these populations $[12,17]$. In this study we analyzed mtDNA genetic relationships between Kenyan black rhinoceros population and the Southern Africa counterpart to assess gene flow between the populations.

\section{Materials and Methods}

2.1. Sample Collections. Samples were collected during rhino translocations exercises between sanctuaries within Kenya between years 2008 and 2012, conducted by KWS rangers and scientist at Nairobi National Park. Blood and ear snips were collected by KWS veterinary officer from anaesthetized animals and preserved in absolute ethanol in cryovials instantly. Materials for laboratory analysis were transported to Molecular Genetics Laboratory, National Museums of Kenya, and preserved.

2.2. DNA Extraction. Portion of skin tissue sample and blood sample precipitates were centrifuged briefly and ethanol aspirated. The samples were left to air-dry then washed in 3 volumes of $1 x$ PBS to rehydrate. DNA was subsequently extracted using Qiagen Kit according to manufacturer's manual (Qiagen Inc., Germantown, MD, USA) essentially involving lysis, binding of DNA to silica matrix, and elution in $200 \mathrm{ul} \mathrm{TE}$ (10 mM Tris HCL, $1 \mathrm{mM}$ EDTA, and $\mathrm{pH} 8.0$ ). For tissues that were difficult to completely lyse, phenol: chloroform method was applied [18]. The blood/tissue was incubated in $50 \mathrm{ug} / \mathrm{ml}$ proteinase $\mathrm{K}, 1 \%$ SDS in STE buffer $(150 \mathrm{mM} \mathrm{NaCl}, 100 \mathrm{mM}$ EDTA, $10 \mathrm{mM}$ Tris $\mathrm{HCl}$, and $\mathrm{pH}$ 7.4) at $55^{\circ} \mathrm{C}$ for $3 \mathrm{hrs}$. The lysate was subjected to phenol: chloroform phase separation and the upper aqueous phase containing DNA aspirated to a new tube. DNA precipitated from the aqueous phase by adding 2-3 volumes of absolute ethanol. The pellet was suspended in 50 to $100 \mathrm{ul} \mathrm{TE}(10 \mathrm{mM}$ Tris HCL, $1 \mathrm{mM}$ EDTA, and $\mathrm{pH}$ 8.0). DNA concentration was measured by absorbance at $260 \mathrm{~nm} / 280 \mathrm{~nm}$ and the quality analyzed by electrophoresis in 1\% Agarose gel in 1x TAE buffer (40 mM Tris acetate, $1 \mathrm{mM}$ EDTA, and $\mathrm{pH} 8.0$ ). The respective tubes with DNA were appropriately labeled and stored at $-20^{\circ} \mathrm{C}$.
2.3. PCR and Product Purification Procedures. In this study 28 DNA samples representing rhinoceros from within Kenya sanctuaries and national parks were analyzed. Polymerase chain reaction was carried out using the following parameters: denaturation at $94^{\circ} \mathrm{C}, 1 \mathrm{~min}$ annealing at $54^{\circ} \mathrm{C}, 45 \mathrm{sec}$., and extension at $72^{\circ} \mathrm{C}$ for $1 \mathrm{~min}$. The primers flanking region of $3^{\prime}$ end of cytochrome $\mathrm{b}$ and D-loop middle region were applied. The amplification product was verified on $1 \%$ agarose gels and the fragment excised from the gel solubilized in sodium iodide solution then bound to (silica) column in the gene clean procedure. Bound DNA was eluted in $30 \mathrm{ul}$ nuclease free $\mathrm{ddH}_{2} \mathrm{O}$.

2.4. Sequencing. Gene cleaned DNA of the amplified fragments were sequenced at Macrogen Inc., Europe (Netherlands), using Sanger's fluorescent dye chain terminator method. Each of the samples was independently sequenced three times and the raw sequences analyzed in Clustal-W program in BioEdit (Version 7.05) to give the consensus but five of the sample sequences did not yield good data and were excluded. The edited raw sequences were submitted to National Center for Biotechnology Information (NCBI: https://www.ncbi.nlm.nih.gov) nucleotide database, GenBank accession numbers: KU569499-KU569508 and KP247507-KP247521.

2.5. Sequence Alignment and Phylogenetic Analysis. Sequences from the dataset were initially aligned utilizing the Clustal-W program in BioEdit and the phylogenetic relationships inferred from the aligned nucleotide sequences by the NJ method (bootstrap 1000 replicates) implemented in the MEGA suite version $6[19,20]$.

Test of neutrality was performed using Tajima's D software implemented in MEGA suite [21, 22] and the analysis of allele diversity haplotypes and population divergence done in DNA sequence polymorphism statistics packages implemented in DnaSP V5 software [23, 24].

\section{Results}

3.1. Distant Phylogenetic Relationship in Rhinoceros Family. Phylogenetic tree clusters generated by NJ method at bootstrap 1000 replicates were rooted against outgroup Dicerorhinus sumatrensis harrissoni indicating long distance evolutionary separation between the white rhinoceros (Ceratotherium simum simum) and the black rhinoceros (D. bicornis) clusters. The two clusters of black rhinoceros (D. b. minor and $D$. b. michaeli) are phylogenetically closely related. Majority of the rhinoceros in both Kenyan and Southern Africa group are monophyletic clusters with insignificant genetic variations while some of the representative lineages have only a few rhinoceros. The Tanzanian rhinoceros population (Figure 1, shown in grey) is an independent lineage of $D$. $b$. michaeli with some admixtures from Kenya population and possible lineage variant represented by D. b. rovumae voucher sample. Some rhinoceros from the South Western Africa (D. b. bicornis) cluster together with the D. b. minor population of Southern Africa while other independent lineages from South Western African population represented 


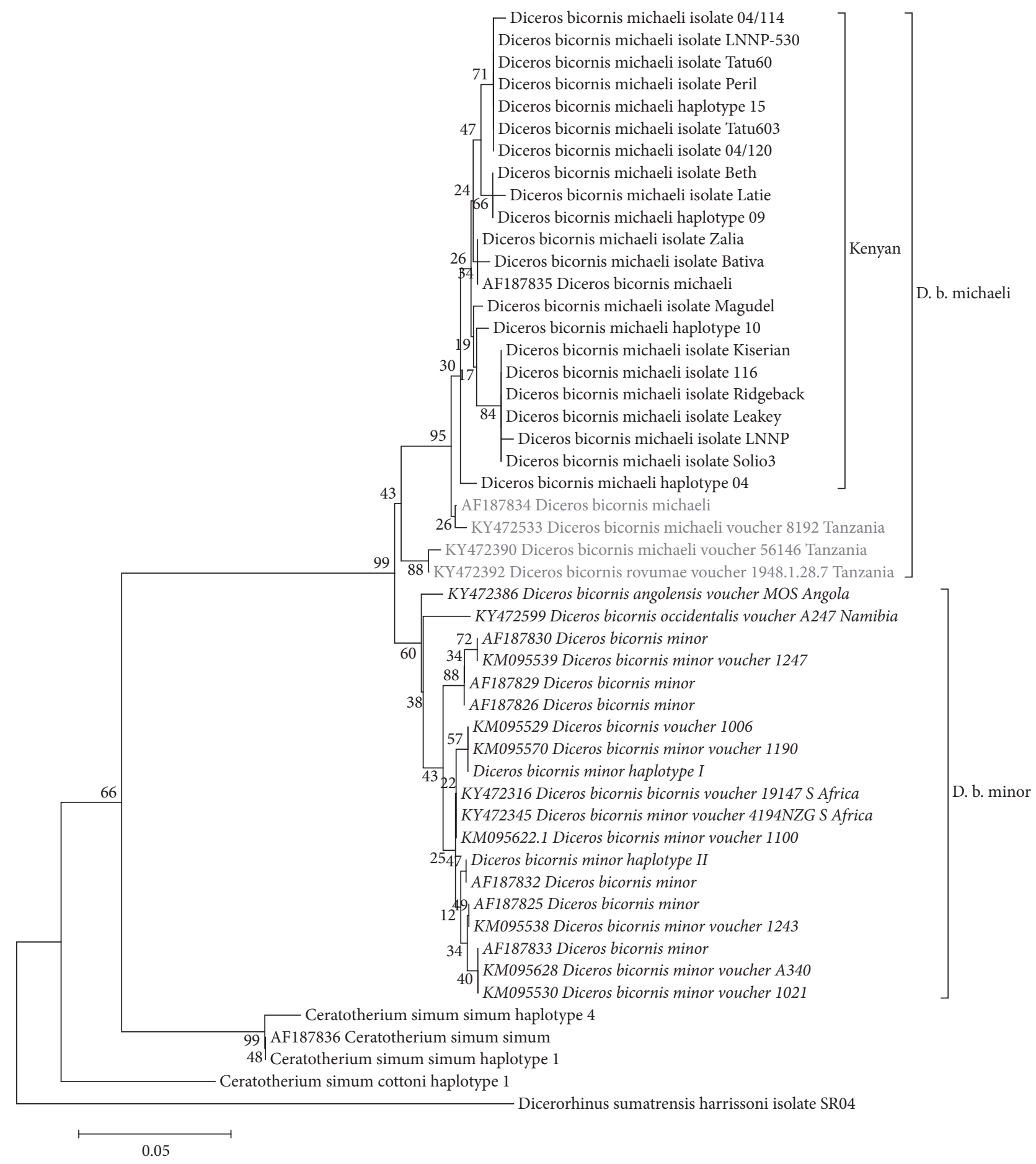

FIGURE 1: Evolutionary relationship among global rhinoceros inferred using the NJ method. The percentage of replicate trees in which the associated taxa clustered together in the bootstrap test (1000 replicates) is shown next to the branches. The tree is drawn to scale, with branch lengths inferring evolutionary distances. The analysis involved 50 nucleotide sequences and there were a total of 254 positions in the final dataset. Analyses were conducted in MEGA6. 
TABLE 1: Tajima’s neutrality test.

\begin{tabular}{lcccccc}
\hline & $m$ & $S$ & $p_{s}$ & $\Theta$ & \multicolumn{1}{c}{. } \\
\hline D. b. minor & 16 & 6 & 0.023529 & 0.007091 & 0.009706 & 1.262277 \\
D. b. michaeli & 16 & 10 & 0.039216 & 0.011818 & 0.011667 & -0.047838 \\
\hline
\end{tabular}

The analysis involved 16 nucleotide sequences. There were a total of 255 positions $(n)$ in the final dataset of each population, D. b. minor and D. b. michaeli.m $=$ number of sequences, $n=$ total number of sites, $S=$ number of segregating sites, $p_{s}=S / n, \Theta=p_{s} / a 1, \pi=$ nucleotide diversity, and $D$ is the Tajima test statistic ( $\pi$ and $S / a 1$ both estimate $\Theta$, where $E$ (expected) $E[\pi]=\Theta$ and $E[S]=a 1 \Theta$ ), software default significant at $P<0.10$. Analyses were conducted in MEGA6.

TABle 2: Diversity differences and genetic divergence between Black Rhinoceros population in Kenyan versus Southern Africa group (significance: $P<0.10$ ) conducted using DnaSP V5 software.

\begin{tabular}{lc}
\hline Population $1: D . b$. michaeli (Kenya) & Population 2: D. $b$. minor (Southern Africa) \\
\hline Number of sequences: 16 & Number of sequences: 16 \\
Number of polymorphic sites (haplotypes): 10 & Number of polymorphic sites (haplotypes): 6 \\
Nucleotide diversity (per site), Pi: 0.01167 & Nucleotide diversity (per site), Pi: 0.00971 \\
Haplotype (gene) diversity: 0.933 & Haplotype diversity, Hd: 0.900 \\
\hline
\end{tabular}

Between populations: number of fixed differences: 7; mutations polymorphic in population 1 but monomorphic in population 2: 9; mutations polymorphic in population 2 but monomorphic in population 1: 5; shared mutations: 1.

by $D . b$. angolensis and $D . b$. occidentallis are monophyletic (Figure 1). In each black rhinoceros population, tree clusters are monophyletic.

3.2. Population Departure from Neutrality. When population is at equilibrium neutrality the nucleotide diversity $(\pi)$ and the number of nucleotide segregating sites $(\Theta)$ are indistinguishable and this is seen in both Southern Africa $(D$. b. minor) and Kenyan (D. b. michaeli) rhinoceros. Tajima$\mathrm{D}$ analysis of Southern Africa rhinoceros dataset showed a positive value while Kenyan group subset had a weak negative value (Table 1).

3.3. DNA Diversity and Divergence between Populations. DNA diversity analysis of similar region of mtDNA of the Kenyan and Southern African rhinoceros showed that the two populations are distinct with only one shared mutation and nine fixed differences. The Southern Africa rhinoceros population had lower haplotype diversity and nucleotide diversity relative to the Kenyan population (Table 2).

\section{Discussion}

Black rhinoceros became critically endangered species in the 1970s mainly due to poaching and historical game hunting during colonial era and also due to expansion of agricultural land in Africa [25-27], prompting implementation of remedial conservation strategies to intensively manage the remaining population within high security sanctuaries [5, 9]. These management fragments started with low numbers of founding population with periodical translocation between the sanctuaries managed in coordination with local government wild life services [7, 28]. The low numbers of founding population have implications in genetic variability and resilience of the subspecies.

The Eastern Africa black rhinoceros (D. b. michaeli) is historically separated from the southern population (D. $b$. minor) although there is no real geographical barrier to limit movement between the two regions. Some authors suggest that each subspecies population may have behavioral adaptations to their local environments $[3,12]$. The two subspecies are not genetically reproductively separated and there have been no rigorous studies on migration and reproductive gene flow between these populations [12]. In this study, phylogenetic analysis of these populations using mtDNA D-loop region (Figure 1) shows that the two populations fall into two different clades that have further separated into monophyla clusters over time. This is concurrent with previous observations that the D. b. michaeli and D. $b$. minor populations become distinct genetically [27, 29, 30]. However, the phylogenetic tree branch lengths of two clades of black rhinoceros are closely linked and are distantly related to white rhinoceros, C. s. simum, and Sumatran rhinoceros, D. s. harrissoni [16], indicating that the Eastern Africa and Southern Africa black rhinoceros separation is recent. The Tanzanian D. b. michaeli cluster has admixtures populations with lineages from Kenya likely at the geographic areas separated by national boundary but also has lineages close to southern black rhinoceros. The voucher specimen, AF187834 (Figure 1), was born in Cincinnati zoo, Ohio, USA, from a Kenya lineage [31] while $D$. b. rovumae voucher is now extinct but has closely related lineages in the southern black rhinoceros that can be used in genetic supplementation [27, 31]. Southwestern Africa black rhinoceros (D. b. bicornis) from Namibia and Angola clustered within the D. b. minor clade. The Southwestern Africa monophyla lineages, for example, D. $b$. congolensis and $D . b$. occidentalis, can further be studied with the aim of providing source of heterogeneity in genetic supplementation of the Southern Africa black rhinoceros population.

Inbreeding depression versus outbreeding depression are concerns in management policies of rhinoceros populations in sanctuaries $[32,33]$. The current sanctuaries hold fragmented pockets of rhinoceros after near demise in the $1970 \mathrm{~s}$ due to anthropologic issues but mainly poaching. Previous studies based mtDNA diversity showed that D. $b$. minor 
population in Southern Africa had only a few haplotypes raising the question of whether these remnant populations lost genetic diversity recently as a result of management fragments gene flow bottleneck or have been a genetically separate lineage for longer time [29]. Tajima's D test analysis in this study showed a positive value for the southern $D$. b. minor population while the Eastern Africa D. b. michaeli population had negative value (Table 1) indicating that the two populations are experiencing different selection pressure. Based on the recent history of demise and restocking of African rhinoceros, it is plausible that the positive Tajima's $\mathrm{D}$ value reflects recent bottleneck in these fragmented population while the Eastern African negative Tajima's D value is a result of recent population expansion from few founding individual rhinoceroses.

For the same sample size the Eastern African D. $b$. michaeli had higher genetic diversity (haplotypes $=10$ ) compared to the Southern Africa D. b. minor (haplotypes = 6 ) with seven fixed differences and only one shared mutation (Table 2). The apparent low diversity in the Southern Africa black rhinoceros infer a population bottleneck [27, 29]. For the mtDNA region analyzed, the fixed nucleotide polymorphic site differences between the two populations were seven with only one shared polymorphic site indicating that gene flow between the Eastern and Southern African and rhinoceros populations is restricted. Since mtDNA is maternally inherited, this may imply that the female rhinoceros founding population has behavioral restricted movements within an ecological range.

There is need to readjust current conservation management paradigms for the black rhinoceros where precaution strategies in the translocation of endangered species bring only small, incremental improvements [27, 28, 34]. Rhinoceros are herbivores without substantial predators and are resilient to ecological challenges [35]; therefore their translocation for restocking to improve genetic diversity is feasible. Since there is no reproductive barrier in African black rhinoceroses, the genetic diversity improvement will involve pilot outbreeding programs among the fragmented populations across the ecological range $[5,27,29]$.

\section{Conflicts of Interest}

The authors declare that there are no conflicts of interest regarding the publication of this paper.

\section{Acknowledgments}

This research project was supported by Molecular Genetics Laboratory at National Museums of Kenya and subgrant from Professor Thomas Gilbert, University of Copenhagen, Natural History Museums, Denmark, to support Masters of Arts Program for Nyamu M. Njagi and Masters of Science dissertation project for David N. Thuo.

\section{References}

[1] J. N. Garnier, M. W. Bruford, and B. Goossens, "Mating system and reproductive skew in the black rhinoceros," Molecular Ecology, vol. 10, no. 8, pp. 2031-2041, 2001.
[2] R. Emslie, "Diceros bicornis," in IUCN 2011. IUCN Red List of Threatened Species. Version 2011.2, 2011, http://www.iucnredlist .org/.

[3] R. Emslie and M. Brooks, "African Rhino Status Survey and Conservation Action Plan," 1999, IUCN/SSC African Rhino Specialist Group. IUCN, Gland, Switzerland and Cambridge, UK.

[4] S. M. Muya, M. W. Bruford, A. W.-T. Muigai et al., "Substantial molecular variation and low genetic structure in Kenya's black rhinoceros: implications for conservation," Conservation Genetics, vol. 12, no. 6, pp. 1575-1588, 2011.

[5] IUCN, "Position statement on the translocation of living organisms: introductions, re-introductions, and re-stocking," 1987, Gland, Switzerland and Cambridge, UK: IUCN, The World Conservation Union.

[6] IUCN SSC AfRSG, "Diceros bicornis," 2008, IUCN red list of threatened species. IUCN 2008.

[7] R. H. Emslie and M. H. Knight, "Update on African rhino status and trends: from IUCN SSC African Rhino Specialist Group (AfRSG)," in Report to CITES Standing Committee 65th Meeting, pp. 1-6, 2014.

[8] D. N. Thuo, J. O. Junga, J. M. Kamau, J. O. Amimo, F. M. Kibegwa, and K. E. Githui, "Population viability analysis of black rhinoceros (Diceros bicornis michaeli) in Lake Nakuru National Park, Kenya," Journal of Biodiversity \& Endangered Species, vol. 3, article 1, 2015.

[9] R. A. Brett, "Conservation Strategy and Management Plan for the Black Rhinoceros (Diceros bicornis) in Kenya," in Rhino Conservation Programme, Kenya Wildlife Service, 1993.

[10] R. H. Emslie, R. Amin, and R. Kock, "Guidelines for the in situ re-introduction and translocation of African and Asian rhinoceros," 2009, Occasional paper of the IUCN Species Survival Commission No. 39.

[11] C. P. Groves, "Geographic variation in the black rhinoceros Diceros bicornis (L., 1758)," Zeitschrift fur Saugetierkunde, vol. 32, pp. 267-276, 1967.

[12] E. H. Harley, I. Baumgarten, J. Cunningham, and C. O’Ryan, "Genetic variation and population structure in remnant populations of black rhinoceros, Diceros bicornis, in Africa," Molecular Ecology, vol. 14, no. 10, pp. 2981-2990, 2005.

[13] R. Frankham, J. D. Ballou, M. D. B. Eldridge et al., "Predicting the probability of outbreeding depression," Conservation Biology, vol. 25, no. 3, pp. 465-475, 2011.

[14] F. W. Allendorf and G. Luikart, Conservation and the Genetics of Populations, Blackwell, Malden, Mass, USA, 2007.

[15] M. Jama, Y. Zhang, R. A. Aman, and O. A. Ryder, "Sequence of the mitochondrial control region, $\mathrm{tRNA}^{\text {thr }}$, tRNS $\mathrm{tR}^{\text {pro }}$ and tRNA $^{\text {phe }}$ genes from the black rhinoceros, Diceros bicornis," Nucleic Acids Research, vol. 21, no. 18, article 4392, 1993.

[16] E. Willerslev, M. T. P. Gilbert, J. Binladen et al., "Analysis of complete mitochondrial genomes from extinct and extant rhinoceroses reveals lack of phylogenetic resolution," $B M C$ Evolutionary Biology, vol. 9, article 95, 2009.

[17] J. C. Avise, J. E. Neigel, and J. Arnold, “Demographic influences on mitochondrial DNA lineage survivorship in animal populations," Journal of Molecular Evolution, vol. 20, no. 2, pp. 99-105, 1984.

[18] J. Sambrook, E. F. Fritsch, and T. Maniatis, Molecular Cloning: A Laboratory Manual, Cold Spring Harbour Laboratory Press, New York, NY, USA, 1989. 
[19] K. Tamura, M. Nei, and S. Kumar, "Prospects for inferring very large phylogenies by using the neighbor-joining method," Proceedings of the National Academy of Sciences of the United States of America, vol. 101, no. 30, pp. 11030-11035, 2004.

[20] K. Tamura, G. Stecher, D. Peterson, A. Filipski, and S. Kumar, "MEGA6: molecular evolutionary genetics analysis version 6.0," Molecular Biology and Evolution, vol. 30, no. 12, pp. 2725-2729, 2013.

[21] F. Tajima, "Statistical method for testing the neutral mutation hypothesis by DNA polymorphism," Genetics, vol. 123, no. 3, pp. 585-595, 1989.

[22] M. Nei and S. Kumar, Molecular Evolution and Phylogenetics, Oxford University Press, New York, NY, USA, 2000.

[23] J. Rozas, J. C. Sánchez-DelBarrio, X. Messeguer, and R. Rozas, "DNAsp, DNA polymorphism analyses by the coalescent and other methods," Bioinformatics, vol. 19, no. 18, pp. 2496-2497, 2003.

[24] P. Librado and J. Rozas, "DnaSP v5: a software for comprehensive analysis of DNA polymorphism data," Bioinformatics, vol. 25, no. 11, pp. 1451-1452, 2009.

[25] E. I. Steinhart, "Hunters, poachers and gamekeepers: Towards a social history of hunting in colonial Kenya," The Journal of African History, vol. 30, no. 2, pp. 247-264, 1989.

[26] A. Thompsell, Hunting Africa: British Sport, African Knowledge and The Nature of Empire (Britain and The World). Introduction: Reconsidering Hunting as A Site of Masculine and Imperial Domination, Palgrave Macmillan, London, UK, 2015.

[27] Y. Moodley, I. M. Russo, D. L. Dalton et al., "Extinctions, genetic erosion and conservation options for the black rhinoceros (Diceros bicornis)," Scientific Reports, vol. 7, Article ID 41417, 2017.

[28] W. L. Linklater, K. Adcock, P. du Preez et al., "Guidelines for large herbivore translocation simplified: black rhinoceros case study," Journal of Applied Ecology, vol. 48, no. 2, pp. 493-502, 2011.

[29] R. M. Anderson-Lederer, W. L. Linklater, and P. A. Ritchie, "Limited mitochondrial DNA variation within South Africa's black rhino (Diceros bicornis minor) population and implications for management," African Journal of Ecology, vol. 50, no. 4, pp. 404-413, 2012.

[30] R. Du Toit, "African rhino systematics-the existing basis for subspecies classification of black and white rhinos," Pachyderm, vol. 9, pp. 3-7, 1987.

[31] S. M. Brown and B. A. Houlden, "Conservation genetics of the black rhinoceros (Diceros bicornis)," Conservation Genetics, vol. 1, no. 4, pp. 365-370, 2000.

[32] L. C. Rookmaaker, "Review of the European perception of the African rhinoceros," Journal of Zoology, vol. 265, no. 4, pp. 365376, 2005.

[33] G. Clinning, D. Druce, D. Robertson, J. Bird, and B. Nxele, Black Rhino in Hluhluwe iMfolozi Park: Historical Records, Status of Current Population and Monitoring and Future Management Recommendations, Ezemvelo KZN Wildlife, Hluhluwe, South Africa, 2009.

[34] W. L. Linklater, J. V. Gedir, P. R. Law et al., "Translocations as experiments in the ecological resilience of anasocial megaherbivore," PLoS ONE, vol. 7, p. e30664, 2012.

[35] J. M. Scott, D. D. Goble, A. M. Haines, J. A. Wiens, and M. C. Neel, "Conservation-reliant species and the future of conservation," Conservation Letters, vol. 3, no. 2, pp. 91-97, 2010. 

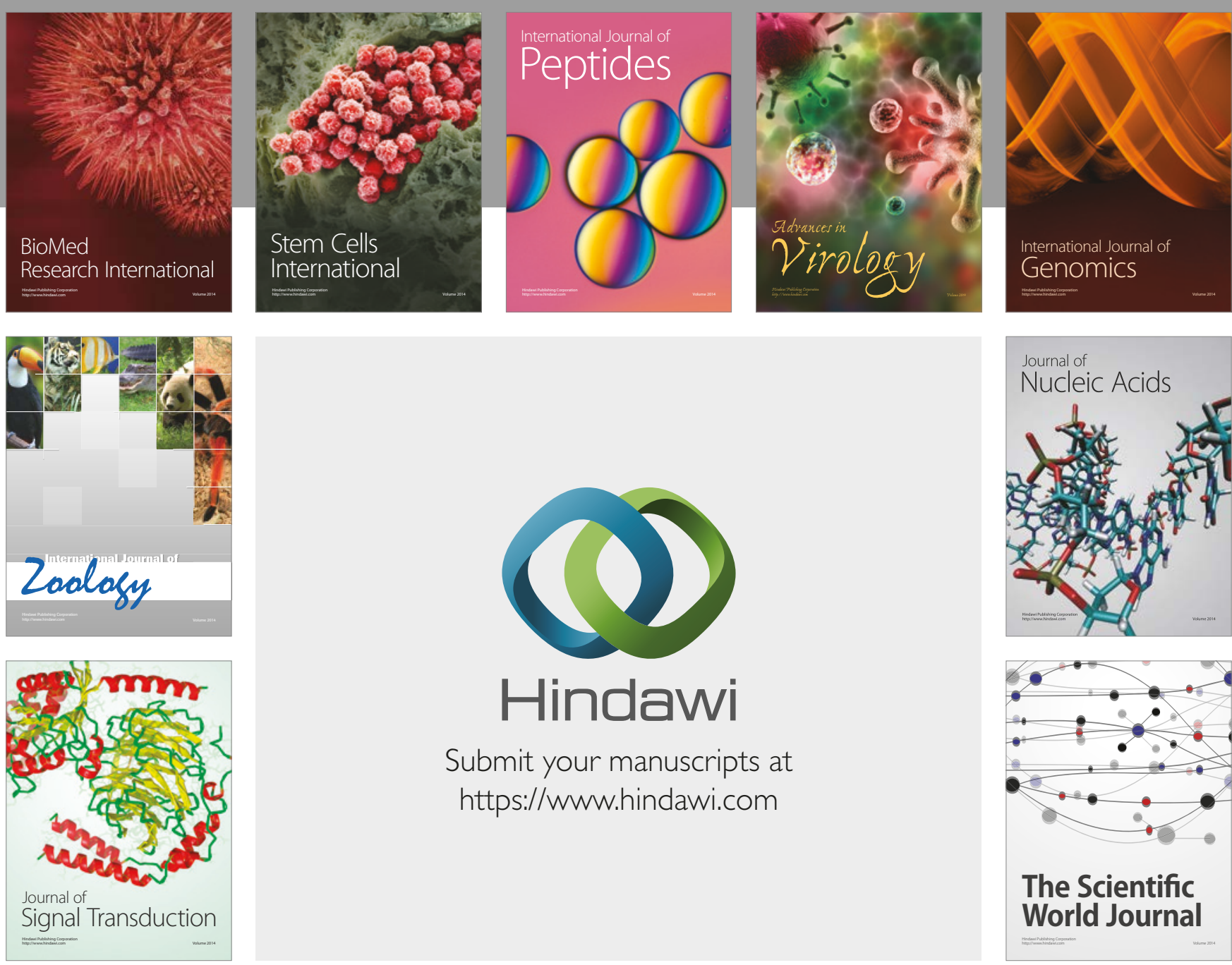

Submit your manuscripts at

https://www.hindawi.com
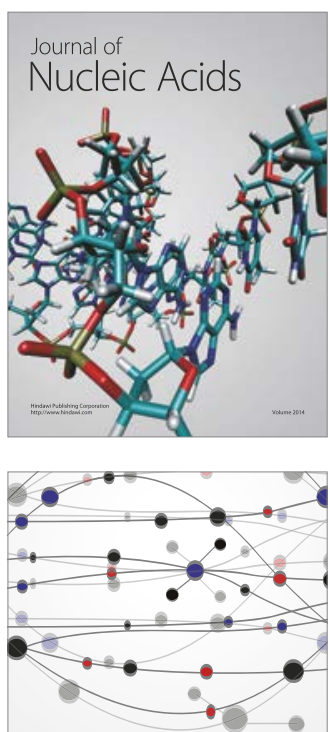

The Scientific World Journal

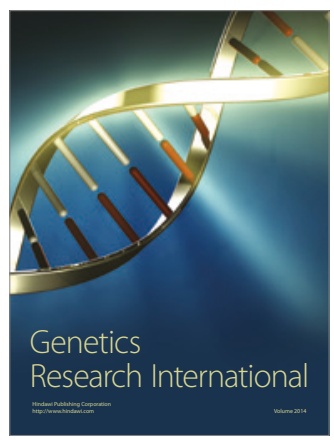

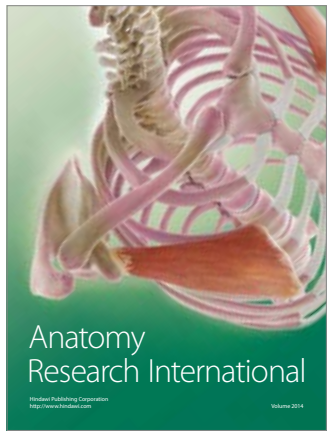

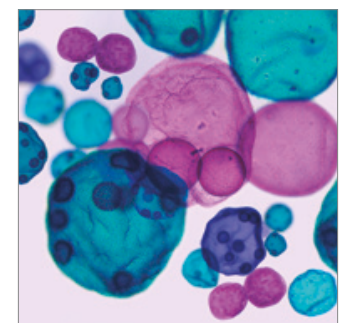

International Journal of Microbiology
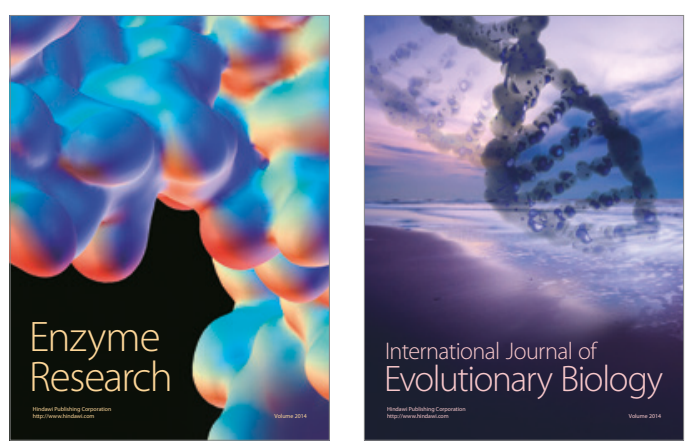
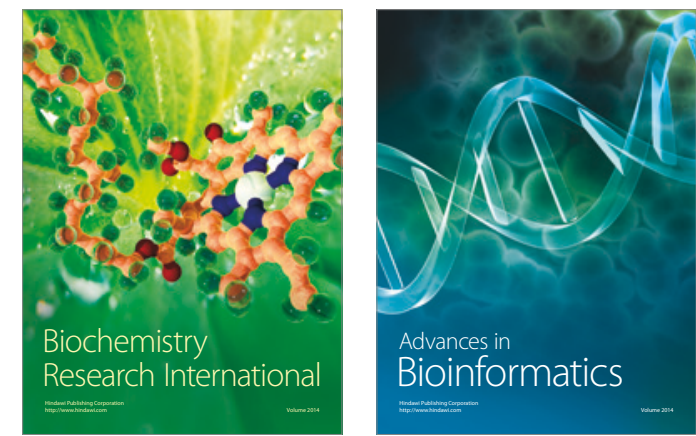

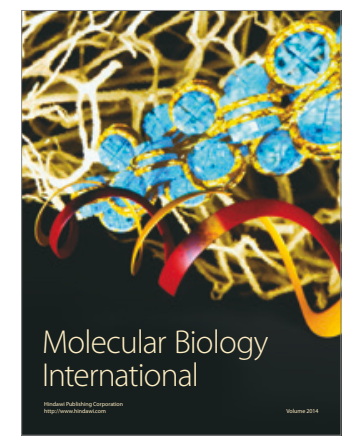

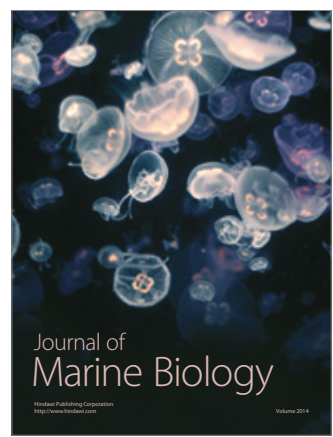

